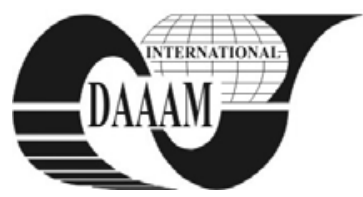

\title{
A FRAMEWORK FOR TIME-AWARE CHANGE MANAGEMENT IN VIRTUAL ENTERPRISES
}

\author{
SAVIMAA, R[aul]; KANGILASKI, T[aivo] \& POLYANTCHIKOV, I[gor]
}

\begin{abstract}
Companies often need integration of business process and their production with others. Processing is time-sensitive and the management framework should encapsulate timing criteria of processes. There is no unified model for integration of process and production information in temporary coalition of co-operating enterprises. The research is aimed to overcome this cap and the current paper describes extension of Enterprise Architecture Management approach for modelling time-dependent processes and change management in cooperating enterprises. As a result, the suggested approach is presented how co-operating companies can exchange production-related time-dependent information in detail.
\end{abstract}

Key words: collaborative engineering, virtual manufacturing, time-aware modelling, enterprise architecture management

\section{INTRODUCTION}

Increasing demands to production quality cause enterprises to improve their planning processes and quality systems. More detailed specification of business processes and production details is used, often in detail understood only inside the company. Global international trends force enterprises to cooperate to achive synergy and gain advantages at the market. Integration of production creates need for exchange related information and the corresponding process should be standardised.

There is no unified model for integration of business process and production information in temporary coalition of co-operating enterprises. The current paper stresses the importance to model also timing requirements and temporal behaviour of processes since in most production environments correct timing criteria have the same importance as algorithmic correctness. Also, there are no widely accepted methods for modelling time-aware co-operation between closely integrated enterprises. Therefore a novel solution is suggested in the paper. The Enterpise Architecture Management (EAM) approach that integrates different views of an enterprise is extended with newly introduced time-aware modelling of processes in time- and safety-critical production environments.

Novelty of the approach is based on emphasizes of importance of modelling timing aspects of processes and applying it for solving interoperability issues for co-operation.

\section{VIRTUAL ENTERPRISES}

VE is defined as a set of companies and/or enterprises that temporarily co-operate to achieve common marketing goals. To increase their competiveness, companies combine their production processes and form a VE for specific period. In such way small and medium companies can more easily compete with large enterprises on the market (Gilmore et al, 2001).

Companies that participate in VE sustain their own goals, indicators, processes and organizational culture. They belong to different maturity level: processes are specified and managed on different level of precision. Setting up a co-operation in VE includes joint planning of business models, production processes, information exchange model and mutual understanding of resource management principles (Polyantchikov et al., 2010). Participants often face with a number of obstacles with integration of often incompatible data models and information systems (Polyantchikov \& Shevtshenko, 2010). It would be easier, if participating companies would use similar description approaches, e.g. an EAM approach, as suggested.

\section{3. MANAGEMENT \\ ARCHITECTURE}

EAM is an approach that stresses the importance to capture the organisation model from all levels and viewpoints of an enterprise: business goals are related to business processes, they accordingly are supported by information systems, information handling and reporting system and infrastructure. There exist a number of EAM approaches, e.g. TOGAF, CIMOSA, FEA, DoDAF, ARCON, ISO/IEC 42010:2007. Those conventional methods consider organisations as single business units and are not specialised for temporary alliances (Kangilaski, 2010).

There are also some general process specification methodologies for production enterprises like UML, Resource allocation diagrams (RAD), Event process chain (EPC) or Function allocation diagrams (FAD).

Resultant modelling should integrate general EAM principles with specific representation and analysis of processes and related attributes (interconnections, information exchange criteria, etc). The current research focuses on enterprises that operate in dynamic environment with specified time limits on processes. Therefore, here also different process timing and interaction scenarios are to be considered and modelled.

\section{MODELLING TIME-AWARE PROCESSES}

Currently there is no suitable methodology to manage timedependent co-operation in VEs. The research suggests an extension to existing frameworks as presented hereunder.

Each organisation that participates in VE has own processes. In order to allow control over producing of combined products, business processes and production schemes of companies are combined following common goals. Processes in participating companies should be described using a common approach. Since conventional EAM methods are not suitable for modelling continuously operating time-critical multifunctional virtual organisations, interaction based specification and modelling methodologies are investigated.

A suitable base candidate is an Enterprise Modelling methodology TEBA (Savimaa, 2006) that stresses the importance to handle the organisation from multiple viewpoints simultaneously: it is based on UML approach that enables to implement the interaction-centred model of computation. UML use case, activity and sequence diagrams are used for describing processes. For analysing the timing correctness of interactions the Q-model (Quirck \& Gilbert, 1977) is used. 


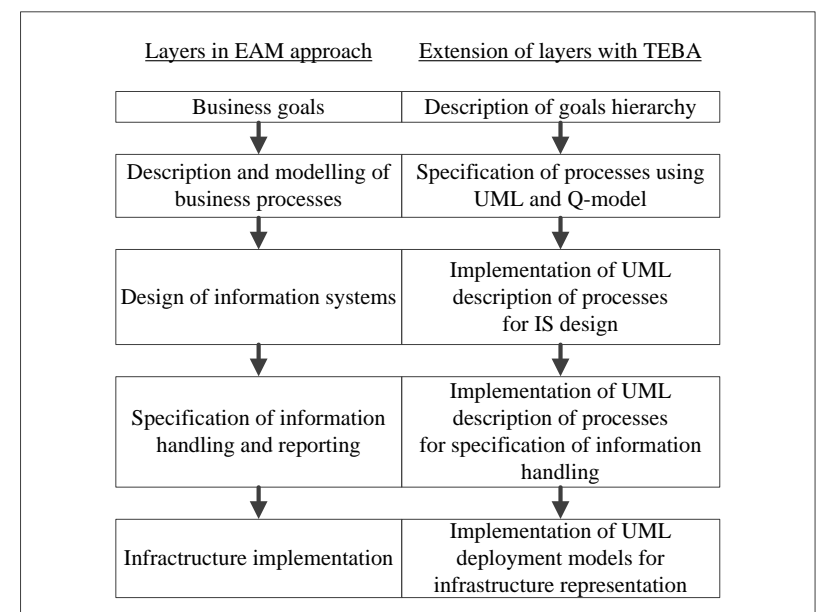

Fig. 1. Layers in EAM framework (left) and their suggested extension using TEBA approach (right)

As an alternative, a similar approach is partially described by Neill and Laplante (2003). Also that approach stresses the importance of modelling time-aware processes using the enhanced version of the Q-model (Motus \& Rodd, 1994).

In TEBA, a model of the organisation describes an organisation from different viewpoints similarly to EAM and captures goals, processes and data management, related information systems, technological solutions and infrastructure and relations between those. As a result of the current research, it is suggested to add a specific component of a model to a general EAM approach on all levels. The components describe processes in more detail also from time-aware point of view. Extension of the suggested EAM is presented on Figure 1. As a result, we have a suitable model to specify processes and related aspects in every participating company of a VE.

\section{TIME-AWARE CHANGE MANAGEMENT IN VIRTUAL ENTERPRISES}

Integration of enterprise models of participating companies in VE is easily done by interrelating corresponding new components of the extended model as illustrated on Figure 2.

The full specification of goals, processes and related parameters in VE is be seen as an EAM process: to reach from the existing goals of participating companies to unified goal of VE is necessary to manage modification projects of information systems, information management, reporting and infrastructure.

Management of extended components of the model can be considered as implementation of change model in TEBA (Savimaa, 2005). In this way EAM is combined with TEBA change management: implementation of change model means that there is an organisation model at initial stage, organisation model of final desired stage and intermediate steps to reach the aim. Based on those models, a stepwise change is devised.

\begin{tabular}{|c|c|c|c|}
\hline Layers in EAM & Company \#1 in VE & \multirow{3}{*}{$\leftrightarrow$} & Company \#2 in VE \\
\hline \multirow{2}{*}{$\begin{array}{l}\text { Business goals layer } \\
\text { Business proceses } \\
\text { layer }\end{array}$} & $\begin{array}{l}\text { Description of goals } \\
\text { hierarchy }\end{array}$ & & $\begin{array}{l}\text { Description of goals } \\
\text { hierarchy }\end{array}$ \\
\hline & $\begin{array}{l}\text { Specification of processes } \\
\text { using UML and Q-model }\end{array}$ & & $\begin{array}{l}\text { Specification of processes } \\
\text { using UML and Q-model }\end{array}$ \\
\hline $\begin{array}{l}\text { Information systems } \\
\text { layer }\end{array}$ & $\begin{array}{l}\text { Implementation of UML } \\
\text { description of processes }\end{array}$ & \multirow{2}{*}{$\leftrightarrow$} & $\begin{array}{l}\text { Implementation of UML } \\
\text { description of processes }\end{array}$ \\
\hline $\begin{array}{l}\text { Information handling } \\
\text { and reporting layer }\end{array}$ & $\begin{array}{l}\text { Implementation of UML } \\
\text { description of processes }\end{array}$ & & $\begin{array}{l}\text { Implementation of UML } \\
\text { description of processes }\end{array}$ \\
\hline Infrasctructure layer & $\begin{array}{l}\text { Implementation of UML } \\
\text { deployment models for } \\
\text { infrastructure } \\
\text { representation }\end{array}$ & & $\begin{array}{l}\text { Implementation of UML } \\
\text { deployment models for } \\
\text { infrastructure } \\
\text { representation }\end{array}$ \\
\hline
\end{tabular}

Fig. 2. Integration of organization models between participating companies/enterprises in virtual enterprise
Modelling results can be checked at every stage using current and prognosticated organisational model of that stage.

The introduced methodology is modelled in test case studies. The results have shown that the approach is in principle suitable, but needs specific additional customisation for each implementation case.

\section{CONCLUSION}

The current paper describes change management for VEs with time-critical business or production processes. Since conventional EAM methods are not suitable for modelling such VEs, a novel approach is introduced in the paper. It extends EAM with detailed modelling of process interactions and timing criteria. The solution is designed for VEs.

The result enables companies that participate in VE, exchange production-related time-dependent information. The current stage of the research indicates that the suggested methodology should be in future specialized for more specific application domains in order to elaborate suitable domainspecific prototypes form the introduced general prototype.

\section{ACKNOWLEDGEMENTS}

The research has been partially financed by Estonian Science Foundation grant ETF7693.

\section{REFERENCES}

Gilmore, A.; Carson, D.; Grant, K. (2001). SME marketing in practice, Marketing Intelligence \& Planning, Vol. 19, No. 1, pp. 6-11, ISSN: 0263-4503

Kangilaski, T. (2010). Communication as a Crucial Element for EAM in VO, Enterprise Architecture, Integration and Interoperability: Proc IFIP TC 5 Intl Conf, Enterprise Architecture, Integration and Interoperability (EAI2N) 2010, Brisbane, Australia, September 2010, ISSN 18684238, ISBN 978-3-642-15508-6, pp. 66 - 77

Motus, L. and Rodd, M. G. (1994). Timing Analysis of RealTime Software, ISBN 978-0080420264, Elsevier Science Ltd, Pergamon, UK

Neill, C. J. \& Laplante, P. A. (2003). Specification of RT imaging systems using the UML, Real-Time Imaging, Elsevier Science Ltd, Vol. 9, pp. 125-137, DOI: 10.1016/S1077-2014(03)00019-6

Quirk, W. \& Gilbert, R. (1977). The formal specification of the requirements of complex real-time system, Atomic Energy Research Establishment, Harwell, rep. no. 8602

Polyanchikov, I.; Pribytkova, M.; Shevtshenko, E. \& Kangilaski, T. (2010). E-Maintenance Framework for the Collaborative Network of SME-S, Annals of DAAAM for 2010 \& Proc of the 21st Intl DAAAM Symposium, 20-23rd Oct 2010, Zadar, Croatia, ISSN 1726-9679, ISBN 978-3901509-73-5, Katalinic, B. (Ed.), pp. 0877-0878, DAAAM Int Vienna

Polyanchikov, I.; Shevtshenko. (2010). Collaborative Framework for Virtual Organisation, DAAAM Proceedings of the 7th Intl conf of DAAAM Baltic Industrial Engineering, 20-24th April 2010, Tallinn, Estonia, ISBN 978-9985-59-982-2, Kyttner, R. (Ed.), pp. 398-403

Savimaa, R. (2005). Modelling Emergent Behaviour of Organisations. Time-aware, UML and agent based approach, Thesis on Informatics and System Engineering C22, ISBN 9985-59-543-2, 212 pp. Tallinn University of Technology, Tallinn, Estonia

Savimaa, R. (2006). Integrating UML, the Q-model and a Multi-Agent Approach in Process specifications and Behavioural Models of Organisations, Journal of Systemics, Cybernetics and Informatics, ISSN 1690-4524, Vol 3, No 4, pp. $45-57$ 